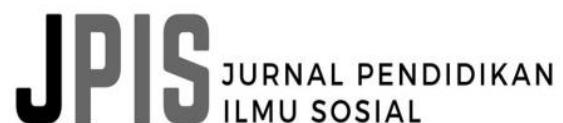

\section{PENERAPAN MODEL PEMBELAJARAN KANCING GEMERINCING UNTUK PEMERATAAN KEAKTIFAN SISWA KELAS IX MATA PELAJARAN IPS DI SMPN 11 MALANG}

\author{
Septika Liaini Sari ${ }^{1}$ \\ 1Program Studi Pendidikan IPS, Universitas Negeri Malang \\ e-mail: septikaliainis@gmail.com
}

\begin{abstract}
This study aimed to determine the difference in activeness using kancing gemerincing model on social studies subjects in class IX of SMPN 11 Malang in the academic year 2019/2020. A quasi-experiment applied in this research with 30 students of grade IX as respondents. The instruments used in this study was test which were consisted of 40 questions and 13 questions on activeness tests. Results showed that the activeness results when implementing kancing gemerincing higher than control class which was implementing PBL models. Results suggest that kancing gemerincing model may be a promising approach to advance student's activeness involvement in social studies courses. This study offers insight into the prospects for any further research.
\end{abstract}

Keywords: kancing gemerincing model, cooperative learning, student's activeness involvement, social studies

Received: 07 April 2020

Accepted: 13 Mei 2020

Published: 15 Juni 2020

\section{PENDAHULUAN}

Belajar merupakan suatu kegiatan yang ditandai dengan adanya perubahan. Perubahan tersebut dapat diketahui dari perubahan tingkah laku seseorang dari yang tidak bisa menjadi bisa. Belajar juga dapat diartikan sebagai proses perubahan seseorang baik dalam hal sikap dan pengetahuan dengan tujuan akan memberikan pengaruh terhadap kesiapan individu dalam merespon situasi yang akan dihadapi (Mulyani, 2013). Sehubungan dengan hal tersebut, Sardiman (2008) menyatakan belajar adalah keterlibatan seseorang baik secara fisik maupun mental dalam pembelajaran. Belajar dapat bermanfaat terhadap proses interaksi dengan lingkungan sekitar. Akan tetapi, dalam pelaksanaannya belajar seringkali mengalami masalah. Salah satu faktor dari masalah tersebut dipengaruhi oleh dominasi beberapa siswa yang ada di dalam kelas. Model pembelajaran yang diterapkan kadang tidak berlangsung secara maksimal. Hal ini dapat terjadi karena masalah dan solusi yang diterapkan tidak sesuai.

Menurut Komalasari (2011) model pembelajaran adalah rencana untuk menyusun kegiatan pembelajaran agar berlangsung lebih terarah sesuai dengan kurikulum yang berlaku. Tujuan model pembelajaran dapat digunakan sebagai pedoman dalam penyusunan materi, tujuan-tujuan pembelajaran, tahap-tahap pembelajaran, serta pengelolaan kelas (Hapsari, 2017). Ketidaksesuaian model pembelajaran dengan masalah yang ada dapat menyebabkan penyelesaian 
masalah tidak optimal. Berdasarkan pengamatan peneliti pada observasi awal yang dilakukan ketika mata pelajaran IPS sedang berlangsung, penerapan model pembelajaran Problem Based Learning (PBL) belum dapat berjalan secara maksimal terhadap keaktifan siswa. Proses keaktifan yang terjadi tidak berlangsung secara merata. Keaktifan dalam pembelajaran hanya didominasi oleh siswa tertentu.

Permasalahan tersebut dapat mengakibatkan pembelajaran tidak berlangsung secara interaktif. Setiap siswa akan sulit aktif untuk mengemukakan pendapatnya sehingga proses belajar tidak dapat berlangsung optimal. Adanya dominasi siswa di dalam kelas mengakibatkan pemerataan keaktifan siswa sulit tercapai.

Salah satu solusi yang diyakini peneliti untuk memecahkan masalah tersebut yaitu dengan menerapkan model pembelajaran kancing gemerincing. Model ini berfokus pada keaktifan siswa agar berlangsung secara merata dengan menggunakan kartu berbicara yang dimiliki oleh masing-masing siswa (Lie, 2010).

Model kancing gemerincing dapat memberikan kesempatan yang rata kepada setiap siswa untuk aktif. Keaktifan siswa adalah keterlibatan siswa dalam setiap pembelajaran (Hamalik, 2008). Keaktifan siswa dapat berupa kegiatan fisik berupa kegiatan menggerakkan badan, bermain, bekerja sama dengan siswa lain, sedangkan kegiatan psikis berupa kegiatan berpikir yang terbentuk dalam rangka pembelajaran (Wibowo, 2016). Keaktifan tersebut dapat lebih mudah diterapkan apabila dikemas dalam sebuah pembelajaran salah satunya dalam bentuk model pembelajaran. Hal ini bertujuan agar siswa tidak merasa bosan ketika pembelajaran sedang berlangsung.

Ciri khas dari model kancing gemerincing yaitu setiap anggota kelompok akan memiliki kesempatan yang sama dalam mengemukakan pendapatnya. Proses pembelajaran menggunakan model ini akan memastikan seluruh siswa dapat aktif mengemukakan pendapatnya. Siswa yang ingin berpendapat harus memberikan kartu berbicara sebagai tiket mengemukakan pendapatnya. Adapun indikator keaktifan dalam penelitian ini yaitu bertanya, menjawab, dan berpendapat.

Berdasarkan latar belakang masalah dan kajian literatur yang telah dipaparkan, penelitian ini bertujuan untuk mendeskripsikan proses penerapan model pembelajaran kancing gemerincing mata pelajaran IPS siswa kelas IX di SMPN 11 Malang, serta mengukur perbedaan pemerataan keaktifan siswa antara kelas kontrol yang menggunakan model pembelajaran PBL, dan kelas eksperimen yang menggunakan model kancing gemerincing.

\section{METODE PENELITIAN}

Penelitian dilakukan di kelas IX di SMPN 11 Malang semester gasal tahun pelajaran 2019/2020. Variabel penelitian terdiri dari bebas yaitu pembelajaran model kancing gemerincing, sedangkan variabel terikat yaitu pemerataan keaktifan siswa. Penelitian ini menggunakan pendekatan kuantitatif dengan metode penelitian eksperimen semu (quasi-experiment). Penelitian kuantitatif merupakan penelitian yang menggunakan angka dan rumus tertentu untuk menguji suatu teori (Subana \& Sudrajat, 2005). Penelitian ini bertujuan untuk mengetahui perbedaan pemerataan keaktifan antara kelas eksperimen dan kelas kontrol. Desain penelitian dalam penelitian ini yaitu: 


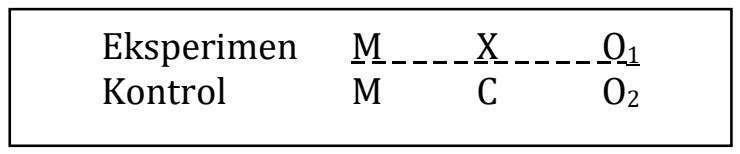

Gambar 1.

Desain Penelitian

Sumber: Emzir (2013)

Keterangan:

$\mathrm{M} \quad$ = Penyetaraan kelas

$\mathrm{X}=$ Penerapan Model Pembelajaran Kancing Gemerincing pada kelas eksperimen

$\mathrm{C}=$ = Pembanding (kelas yang tidak diajar menggunakan model kancing gemerincing)

$\mathrm{O}_{1} \quad=$ Tes dan keaktifan kelas eksperimen

$\mathrm{O}_{2} \quad=$ Tes dan keaktifan kelas kontrol

Populasi dalam penelitian ini adalah siswa kelas IX SMP Negeri 11 Malang dari kelas IX A - IX H. Penelitian ini menggunakan kelas IX A sebagai kelas kontrol yaitu kelas yang diterapkan model Problem Based Learning dan IX B sebagai kelas eksperimen yaitu kelas yang diterapkan model kancing gemerincing. Teknik sampling yang digunakan adalah teknik purposive atau judgmental sampling (Ary, Jacobs, Sorensen, \& Razavieh, 2010; Creswell, 2012). Teknik ini digunakan agar pemilihan kedua kelas yang akan digunakan sebagai kelas kontrol dan kelas eksperimen dipilih sesuai nilai dengan hasil yang relatif sama.

Prosedur penelitian diawali dengan tahap persiapan yang meliputi pembuatan instrumen penelitian berupa RPP, LKPD, materi, dan soal. Instrumen pengukuran keaktifan dalam penelitian ini menggunakan tes keaktifan dengan di dukung hasil observasi keaktifan melalui soal kuis yang diberikan. Instrumen observasi keaktifan dalam penelitian ini menggunakan indikator keaktifan yaitu siswa bertanya, menjawab, dan berpendapat. Indikator tersebut mewakili keaktifan siswa baik dari segi fisik maupun psikis. Kemudian, tes keaktifan berjumlah 13 soal, 10 soal pilihan ganda dan 3 soal uraian. Soal yang diterlebih dahulu diuji validitas dan reliabilitasnya sebelum digunakan untuk penelitian. Peneliti bekerja sama dengan observer yang merupakan teman sejawat dan guru mata pelajaran IPS untuk mengumpulkan data sesuai instrumen.

Teknik analisis data dalam penelitian ini menggunakan statistik deskriptif dan inferensial untuk menguji hipotesis dengan menggunakan program SPSS. Analisis deskriptif digunakan untuk mengetahui keterlaksanaan pembelajaran dengan bantuan angket, sedangkan pemerataan keaktifan siswa dengan bantuan lembar observasi. Kedua instrumen tersebut diisi oleh observer. Adapun kriteria keterlaksanaan pembelajaran disajikan pada Tabel 1. berikut:

Tabel 1.

Kriteria Keterlaksanaan Pembelajaran

\begin{tabular}{lll}
\hline No. & Indikator & Rentang Nilai \% \\
\hline 1. & Sangat Baik & $76-100$ \\
2. & Baik & $51-75$ \\
3. & Kurang Baik & $26-50$ \\
4. & Sangat Kurang & $0-25$ \\
\hline
\end{tabular}

Sumber: (Widayanti, 2019) 
Analisis inferensial yang digunakan yaitu uji normalitas data dengan Kolmogorovsmirnov, uji homogenitas dengan Levene statistics, dan uji hipotesis dengan independent sample t-test untuk mengetahui perbedaan pemerataan keaktifan siswa.

\section{HASIL PENELITIAN DAN PEMBAHASAN}

\section{Proses Penerapan Model Pembelajaran Kancing Gemerincing}

Penelitian dilaksanakan dalam tiga tahap yaitu tahap observasi awal, pelaksanaan, dan pelaporan. Pada tahap observasi awal dilakukan selama enam minggu dengan mengamati proses pembelajaran yang sedang berlangsung dan mengetahui permasalahan yang terjadi. Tahap pelaksanaan dilakukan sebanyak empat kali masing-masing dua pertemuan pada kelas eksperimen dan dua pertemuan pada kelas kontrol. Berikut ini disajikan tabel kegiatan pembelajaran pada pertemuan pertama dan kedua di kelas eksperimen.

Tabel 2.

Proses Penerapan Model di Kelas Eksperimen

\begin{tabular}{|c|c|c|}
\hline Pertemuan & Kegiatan & Uraian Kegiatan \\
\hline \multirow[t]{8}{*}{ Pertama } & Awal & $\begin{array}{l}\text { 1. Berdoa dan mengucapkan salam } \\
\text { 2. Guru memberikan apersepsi berupa pertanyaan } \\
\text { pembuka mengenai materi sebagai awal untuk } \\
\text { mengetahui kemampuan siswa }\end{array}$ \\
\hline & Inti & $\begin{array}{l}\text { 1. Guru menjelaskan skenario kegiatan yang akan } \\
\text { dilaksanakan } \\
\text { 2. Mengintruksikan semua siswa untuk membentuk } \\
\text { kelompok }\end{array}$ \\
\hline & & 3. Membagikan LKPD sebagai bahan diskusi \\
\hline & & $\begin{array}{l}\text { 4. Presentasi dilakukan oleh masing-masing kelompok } \\
\text { yang telah selesai mengerjakan LKPD }\end{array}$ \\
\hline & & $\begin{array}{l}\text { 5. Kelompok lain menyimak kelompok yang sedang } \\
\text { melakukan presentasi }\end{array}$ \\
\hline & Akhir & $\begin{array}{l}\text { 1. Guru bersama siswa menarik kesimpulan materi dan } \\
\text { pembelajaran yang telah dilaksanakan }\end{array}$ \\
\hline & & $\begin{array}{l}\text { 2. Guru menyampaikan materi yang akan dipelajari pada } \\
\text { pertemuan berikutnya }\end{array}$ \\
\hline & & 3. Kegiatan diakhiri dengan doa dan salam \\
\hline \multirow[t]{7}{*}{ Kedua } & Awal & 1. Berdoa dan mengucapkan salam \\
\hline & & $\begin{array}{l}\text { 2. Guru memberikan pertanyaan pembuka sebagai awal } \\
\text { untuk mengetahui kemampuan siswa }\end{array}$ \\
\hline & Inti & $\begin{array}{l}\text { 1. Guru menginstruksikan siswa berkumpul bersama } \\
\text { kelompok yang telah dibentuk pada pertemuan } \\
\text { sebelumnya }\end{array}$ \\
\hline & & 2. Guru mereview materi \\
\hline & & $\begin{array}{l}\text { 3. Guru menjelaskan skenario kegiatan yang akan } \\
\text { dilaksanakan mengenai tata cara bermain } \\
\text { menggunakan kartu model kancing gemerincing. }\end{array}$ \\
\hline & & $\begin{array}{l}\text { 4. Permainan berlangsung secara kelompok, akan tetapi } \\
\text { perhitungan poin keaktifan dihitung individu. }\end{array}$ \\
\hline & & $\begin{array}{l}\text { 5. Kelompok yang anggotanya paling banyak dan cepat } \\
\text { menempelkan kartu berbicara, maka ia akan menjadi } \\
\text { pemenang. }\end{array}$ \\
\hline
\end{tabular}




\begin{tabular}{|c|c|c|}
\hline Pertemuan & Kegiatan & Uraian Kegiatan \\
\hline & Akhir & $\begin{array}{l}\text { 6. Proses bermain kuis dilakukan sampai seluruh soal } \\
\text { ditampilkan. } \\
\text { 7. Kegiatan selanjutnya melalukakan perhitungan jumlah } \\
\text { poin keaktifan dari masing-masing kelompok dan } \\
\text { penentuan kelompok yang menjawab dengan benar } \\
\text { dan cepat. } \\
\text { 1. Kemudian, guru bersama dengan siswa menarik } \\
\text { kesimpulan mengenai pembelajaran yang telah } \\
\text { dilakukan. } \\
\text { 2. Kegiatan akhir dengan mengerjakan tes keaktifan oleh } \\
\text { siswa pada lembar kerja yang tersedia. } \\
\text { 3. Kegiatan di tutup dengan mengucapkan doa dan } \\
\text { salam. }\end{array}$ \\
\hline
\end{tabular}

Hasil observasi mengenai keterlaksanaan pembelajaran kancing gemerincing disajikan pada tabel berikut.

Tabel 3.

Hasil Observasi Pelaksanaan Pembelajaran Kancing Gemerincing oleh Observer

\begin{tabular}{|c|c|c|c|c|c|}
\hline \multirow{2}{*}{ No. } & \multirow{2}{*}{ Indikator } & \multicolumn{2}{|c|}{$\mathbf{O}_{1}$} & \multicolumn{2}{|c|}{$\mathbf{O}_{2}$} \\
\hline & & $\mathbf{P}_{1}$ & $\mathbf{P}_{2}$ & $\mathbf{P}_{1}$ & $\mathbf{P}_{2}$ \\
\hline 1. & Kegiatan Pembuka & 17 & 18 & 20 & 19 \\
\hline 2. & Kegiatan Inti & 37 & 39 & 38 & 39 \\
\hline & Kegiatan Penutup & 6 & 7 & 6 & 7 \\
\hline \multicolumn{2}{|c|}{ Jumlah } & 60 & 64 & 64 & 65 \\
\hline \multicolumn{2}{|c|}{ Jumlah Rata-rata Hasil Observer } & \multicolumn{2}{|c|}{62} & \multicolumn{2}{|c|}{64.5} \\
\hline
\end{tabular}

\section{Keterangan:}

$\mathrm{P}_{1}$ : Pertemuan Pertama

$\mathrm{P}_{2}$ : Pertemuan Kedua

$\mathrm{O}_{1}$ : Observer Guru Mata Pelajaran

$\mathrm{O}_{2}$ : Observer Rekan Mahasiswa Peneliti

Proses keterlaksanaan pembelajaran menggunakan model kancing gemerincing dapat terlaksana dengan kriteria "sangat baik" sesuai dengan Tabel 3 di atas. Berikut dijelaskan perhitungan dari angka dalam tabel 3.

Skor Perolehan Keterlaksanaan Pembelajaran oleh $\mathrm{O}_{1}$

$$
\begin{aligned}
\mathrm{N} & =\frac{\sum \text { Skor Perolehan }}{\sum \text { Skor Total }} \times 100 \% \\
\mathrm{~N} & =\frac{62}{72} \times 100 \% \\
\mathrm{~N} & =86 \%
\end{aligned}
$$

Skor Perolehan Keterlaksanaan Pembelajaran oleh $\mathrm{O}_{2}$

$\mathrm{N}=\frac{\sum \text { Skor Perolehan }}{\sum \text { Skor Total }} \times 100 \%$

$\mathrm{N}=\frac{64,5}{72} \times 100 \%$

$\mathrm{N}=89.6 \%$ 
Hasil pengukuran keterlaksanaan pembelajaran dilakukan dengan cara menghitung jumlah keseluruhan skor yang diperoleh dibagi dengan skor total kemudian dikalikan 100\%. Sehingga diperoleh diperoleh presentase dari observer 1 sebesar 86\% dengan kriteria sangat baik dan observer 2 sebesar 89.6\% dengan kriteria sangat baik. Kedua hasil presentase di atas dibagi dua untuk mengetahui rata-rata presentase yaitu sebesar $87.8 \%$ dengan kriteria sangat baik.

Senada dengan hasil penelitian ini, Endang \& Sore (2016) menjelaskan bahwa model pembelajaan kancing gemerincing meningkatkan minat siswa sehingga meningkatkan partisipasi dan keaktifan siswa jika dibandingkan dengan model pembelajaran lainnya. Selain itu, keterlaksanaan pembelajaran dengan model kancing gemerincing juga dapat meningkatkan aktivitas siswa, yang sejalan dengan hasil penelitian ini, yaitu terjadi peningkatan aktivitas belajar yang lebih baik dibandingkan dengan model pembelajaran sebelumnya (Azizah, Gummah, \& Sukroyanti, 2019).

\section{Penerapan Model Pembelajaran Kancing Gemerincing untuk Pemerataan Keaktifan Siswa}

Hasil penelitian yang dilaksanakan untuk menguji pemerataan keaktifan pada penelitian ini diuji dengan uji hipotesis yaitu uji independent sample t-test. Berikut merupakan hasil uji hipotesis dengan menggunakan independent sample t-test.

Tabel 4.

Hasil Uji Hipotesis Independent Sample t-test

\begin{tabular}{|c|c|c|c|c|c|c|c|c|c|c|}
\hline & & $\begin{array}{r}\text { Leve } \\
\text { Test } \\
\text { Equal } \\
\text { Varia }\end{array}$ & $\begin{array}{l}\text { ne's } \\
\text { for } \\
\text { ity of } \\
\text { nces }\end{array}$ & \multicolumn{7}{|c|}{ t-test for Equality of Means } \\
\hline & & \multirow[b]{2}{*}{$\mathbf{F}$} & \multirow[b]{2}{*}{ Sig. } & \multirow[b]{2}{*}{$\mathbf{t}$} & \multirow[b]{2}{*}{ df } & \multirow{2}{*}{$\begin{array}{l}\text { Sig. } \\
\text { (2- } \\
\text { taile } \\
\text { d) }\end{array}$} & \multirow{2}{*}{$\begin{array}{c}\text { Mean } \\
\text { Differ } \\
\text { ence }\end{array}$} & \multirow{2}{*}{$\begin{array}{c}\text { Std. } \\
\text { Error } \\
\text { Differe } \\
\text { nce }\end{array}$} & \multicolumn{2}{|c|}{$\begin{array}{c}95 \% \\
\text { Confidence } \\
\text { Interval of the } \\
\text { Difference }\end{array}$} \\
\hline & & & & & & & & & Lower & Upper \\
\hline \multirow[t]{2}{*}{ Keaktifan } & $\begin{array}{l}\text { Equal } \\
\text { variances } \\
\text { assumed }\end{array}$ & 1.011 & .319 & 2.263 & 58 & .027 & 8.500 & 3.756 & .982 & 16.018 \\
\hline & $\begin{array}{l}\text { Equal } \\
\text { variances } \\
\text { not assumed }\end{array}$ & & & 2.263 & 57.171 & .027 & 8.500 & 3.756 & .980 & 16.020 \\
\hline
\end{tabular}

Sumber: Hasil Output SPSS

Hasilnya nilai sig (2-tailed) sebesar 0,027, perlu diingat untuk dasar pengambilan keputusan dapat melihat nilai sig 0,05. Apabila nilai sig (2-tailed) $\geq 0,05$ maka $\mathrm{H}_{\mathrm{o}}$ diterima dan $\mathrm{H}_{1}$ ditolak, sedangkan jika nilai sig (2-tailed) $<0,05$ maka $\mathrm{H}_{\mathrm{o}}$ ditolak dan $\mathrm{H}_{1}$ diterima. Hasil uji hipotesis menunjukkan bahwa nilai sig (2-tailed) lebih kecil dari 0,05 sehingga $\mathrm{H}_{\mathrm{o}}$ ditolak dan $\mathrm{H}_{1}$ diterima. Kesimpulan dari hasil tersebut, terdapat perbedaan pemerataan keaktifan ketika diterapkan model pembelajaran kancing gemerincing antara kelas A sebagai kelas kontrol dan kelas B sebagai kelas eksperimen. Kelas kontrol memiliki kecenderungan keaktifan yang tidak merata, 
dibanding kelas eksperimen. Hasil tersebut juga diikuti dengan skor penyebaran keaktifan di kelas eksperimen dan kontrol menggunakan kartu berbicara yang disajikan pada Tabel 5 dan Tabel 6.

Tabel 5.

Distribusi Frekuensi Pemerataan Keaktifan Siswa Kelas IX B (Kelas Eksperimen)

\begin{tabular}{rlr}
\hline \multicolumn{1}{l}{ Skor } & F & Presentase \\
\hline 6 & 1 & $3.3 \%$ \\
5 & 3 & $10 \%$ \\
4 & 2 & $6.6 \%$ \\
3 & 3 & $10 \%$ \\
2 & 8 & $26.6 \%$ \\
1 & 6 & $20 \%$ \\
0 & 7 & $23.3 \%$ \\
\hline Jumlah & 30 & \\
\hline
\end{tabular}

Tabel 6.

Distribusi Frekuensi Pemerataan Keaktifan Siswa Kelas IX B (Kelas Eksperimen)

\begin{tabular}{ccr}
\hline Skor & F & Presentase \\
\hline 6 & 0 & $0 \%$ \\
5 & 0 & $0 \%$ \\
4 & 0 & $0 \%$ \\
3 & 0 & $0 \%$ \\
2 & 30 & $100 \%$ \\
1 & 0 & $0 \%$ \\
0 & 0 & $0 \%$ \\
\hline Jumlah & 30 & \\
\hline
\end{tabular}

Presentase di atas diperoleh dari jumlah perhitungan skor siswa ketika menjawab soal kuis keaktifan yang ditampilkan pada LCD menggunakan kartu berbicara. Setiap slide-nya terdapat salah satu soal bertanya, menjawab, atau berpendapat. Masing-masing soal dengan indikator tersebut ditampilkan secara acak. Siswa yang berhasil menjawab akan dicatat sebagai poin keaktifan.

Kelas IX A sebagai kelas kontrol memiliki persebaran keaktifan siswa yang tidak merata. Hal ini ditunjukkan dengan siswa yang memperoleh skor 6 sebanyak 1 siswa, 5 sebanyak 3 siswa, 4 sebanyak 2 siswa, 3 sebanyak 3 siswa, 2 sebanyak 8 siswa, 1 sebanyak 6 siswa, dan yang tidak menjawab soal keaktifan sebanyak 7 siswa. Skor 6 berarti siswa tersebut menjawab soal keaktifan sebanyak enam kali, begitu pula dengan skor lainnya.

Berdasarkan Tabel 5 dan Tabel 6, dapat diketahui pemerataan keaktifan siswa pada kelas eksperimen lebih merata dibanding kelas kontrol. Siswa pada kelas eksperimen sebanyak 30 siswa memperoleh skor 20 dengan perolehan presentase $100 \%$ yang menunjukkan bahwa seluruh siswa aktif menjawab soal keaktifan. Sehingga, dapat disimpulkan bahwa ada perbedaan penerapan model pembelajaran kancing gemerincing untuk pemerataan keaktifan siswa.

Demikian halnya dengan hasil penelitian oleh Afianti, Sulastry, \& Alimin (2017); Dewi, Sugiarta, \& Suarsana (2015); Krisnawati, Yuliani, \& Indana (2017) yang sejalan mengatakan bahwa keaktifan siswa, hasil belajar siswa merupakan dampak positif yang ditimbulkan dengan adanya penerapan model pembelajaran 
kancing gemerincing. Ini terjadi tidak hanya pada mata pelajaran IPS saja, akan tetapi juga pada pembelajaran Matematika dan IPA.

\section{KESIMPULAN}

Penerapan model pembelajaran kancing gemerincing dapat terlaksana sesuai dengan rencana pelaksanaan pembelajaran. Seluruh siswa mampu terlibat aktif dalam pembelajaran menggunakan model kancing gemerincing. Berdasarkan data penelitian yang telah dipaparkan di atas penerapan model kancing gemerincing dapat memberikan perbedaan keaktifan siswa pada kelas eksperimen dan kelas kontrol. Hal ini terbukti dari hasil uji hipotesis dengan uji independent sampe test melalui SPSS 16.0 bahwa $\mathrm{H}_{0}$ pemerataan keaktifan siswa ditolak dengan hasil uji sebesar $0,027<0,05$.

Data keaktifan siswa pada lembar observasi menunjukkan bahwa keaktifan belajar pada kelas eksperimen lebih kondusif dan merata dengan menggunakan kartu berbicara. Selain itu, rata-rata keaktifan belajar siswa pada kelas kontrol sebesar 71,5 dan eksperimen sebesar 78,5 yang diukur melalui tes keaktifan siswa. Sehingga melalui hasil tersebut dapat disimpulkan bahwa ada perbedaan pemerataan keaktifan siswa yang diterapkan model kancing gemerincing dan yang tidak pada mata pelajaran IPS kelas IX di SMP Negeri 11 Malang. Berdasar hasil penelitian, peneliti selanjutnya direkomendasikan untuk dapat menerapkan model pembelajaran kancing gemerincing ini dengan variabel yang lain yang masih jarang diteliti, misalnya mengenai sikap spiritual siswa dan $21^{\text {st }}$ century skills siswa.

\section{DAFTAR PUST AKA}

Afianti, N. W., Sulastry, T., \& Alimin, A. 2017. Penerapan Model Pembelajaran Kooperatif Tipe Kancing Gemerincing untuk Meningkatkan Keaktifan dan Hasil Belajar Peserta Didik Kelas X MIA 3 SMAN 1 Bontomarannu. Jurnal Nalar Pendidikan, 5 (2), 545-551.

Ary, D., Jacobs, L. C., Sorensen, C., \& Razavieh, A. 2010. Introducation to Research in Education (8th ed.; C. Shortt, ed.). California: Cengage Learning.

Azizah, M., Gummah, S., \& Sukroyanti, B. A. 2019. Artikel Penelitian/ Article Reviu Penerapan Model Pembelajaran Kooperatif Teknik Kancing Gemerincing untuk Meningkatkan Aktivitas Siswa. Jurnal Penelitian dan Pengajian Ilmu Pendidikan: E-Saintika, 2 (2), 127-134.

Creswell, J. W. 2012. Educational Research: Planning, Conducting, and Evaluating Quantitative and Qualitative Research (Fourth). Boston: Edward Brothers, Inc. 
Dewi, M. A., Sugiarta, I. M., \& Suarsana, I. M. 2015. Penerapan pembelajaran kooperatif teknik kancing gemerincing untuk meningkatkan keaktifan dan prestasi belajar matematika siswa sd. Jurnal Pendidikan Matematika Undiksha, 3 (1), 1-10.

Emzir, P. 2013. Metode Penelitian Pendidikan. Jakarta: Rajawali.

Endang, E., \& Sore, A. D. 2016. Peningkatan Hasil Belajar Siswa Melalui Model Kancing Gemerincing di Kelas VIII Sekolah Menengah Pertama Negeri 7 Belimbing. Jurkami: Jurnal Pendidikan Ekonomi, 1 (1), 45-53.

Hamalik. O. 2008. Perencanaan Pengajaran Berdasarkan Pendekatan Sistem. Jakarta: PT Bumi aksara.

Hapsari, A. 2017. Penerapan Model Pembelajaran Kooperatif Tipe Number Heads Together Berbantuan Media Interaktif untuk Meningkatkan Aktivitas dan Prestasi Belajar Siswa, Scholaria, 7 (1), 1-9.

Komalasari. 2011. Pembelajaran Kontekstual Konsep dan Aplikasi. Bandung: PT Refika Aditama.

Krisnawati, N. M., Yuliani, Y., \& Indana, S. 2017. Penerapan Model Pembelajaran Kooperatif Teknik Kancing Gemerincing pada Materi Ekosistem Kelas X SMA Negeri 4 Sidoarjo. Hikmah, XIII (1), 21-35.

Lie, A. 2010. Cooperative Learning Mempraktikkan Cooperative Learning di RuangRuang Kelas. Jakarta: Grasindo.

Mulyani, D. 2013. Hubungan Kesiapan Belajar Siswa dengan Prestasi Belajar, Jurnal Ilmiah Konseling, 2 (1), 27-31.

Qomari, R. 2009. Teknik Penelusuran Analisis Data Kuantitatif dalam Penelitian Kependidikan, Jurnal Pemikiran Alternative Kependidikan, 14 (3), 527-539.

Sanjaya, W. 2008. Perencanaan dan Desain Sistem Pembelajaran. Jakarta: Kencana Prenada Media Group.

Sardiman, A. 2008. Interaksi dan Motivasi Belajar Mengajar. Raja Grafindo Persada: Jakarta.

Subana \& Sudrajat. 2005. Dasar-Dasar Penelitian Ilmiah. Bandung: Pustaka Setia.

Wibowo, N. 2016. Upaya Peningkatan Keaktifan Siswa Melalui Pembelajaran Berdasarkan Gaya Belajar di SMK Negeri 1 Saptosari. Jurnal Electronics, Informatics, and Vocational Education (ELINVO), 1 (2), 128-139. 
Widayanti, D. 2019. Penggunaan Model Pembelajaran TGT untuk Meningkatkan Motivasi dan Hasil Belajar Meyakini Adanya Hari Akhir pada Siswa Kelas Vi SD Negeri 3 Jaten Kecamatan Selogiri Kabupaten Wonogiri Semester I Tahun Pelajaran 2018/2019. Jurnal Pendidikan Konvergensi, 30 (VII), 7-22. 